\title{
Parasitological and epidemiological studies of Wuchereria bancrofti in Imobi, ljebu East, Local Government Area of Ogun State, South Western Nigeria
}

\author{
Okonofua Christiana' ${ }^{1}$, Akinsanya Bamidele ${ }^{2^{*}}$, Idowu Emmanuel Taiwo ${ }^{2}$ and Otubanjo Adetoro Olubunmi ${ }^{2}$
}

\begin{abstract}
Background: Lymphatic filariasis is a mosquito-borne parasitic disease caused by Wuchereria bancrofti. It is a neglected tropical disease that constitutes a public health challenge in rural endemic communities in Nigeria. This is a debilitating disease of global concern, because of its effect on per capital income and its stigmatization on affected individuals. The Program for Elimination for Lymphatic filariasis has set a goal towards possible elimination.

Results: Communities in Imobi, in ljedu East Local Government Area in Ogun State, have been undergoing Mass Drug Administration (MDA). However, there is need for a baseline data to assess, monitor and evaluate the progress of MDA in these communities towards eventual elimination. Systematic random sampling and cluster survey were used to gather 246 participants from six communities in Imobi to a central point at the Local Government Health Centre. Parasitological diagnosis was done using microscopy, while structured questionnaires, which probed into respondents Knowledge, Attitude and Practices, were administered. An overall prevalence of 50 (20.3\%) was observed with 17 (21.5\%) males being more infected than 24 (19.8\%) females. Prevalence of infection was significantly higher in younger age groups 4 (28.6\%) than in older age groups $20(14.6 \%)$ at $p<0.05$. Overall microfilarial density of $25.7 \mathrm{mf} /$ $\mathrm{ml}$ was obtained among infected population. Microfilariae prevalence was not observed in people that had received treatment with both albendazole and ivermectin. Higher prevalence of infection was observed in people who did not made use of Long Lasting Insecticidal Nets 45 (21.1\%), than in people who did 5 (15.2\%). However, it was not statistically significant $(p>0.05)$. Most of the respondents had little or no knowledge of the disease, its cause, transmission, prevention and treatment. The prevalence level is also higher than 1\% for which MDA is required.
\end{abstract}

Conclusions: It is recommended that MDA be intensified in the study area, together with vector control and awareness campaign on the disease.

Keywords: Lymphatic filariasis, Prevalence, Microfilaria density, Antifilarial drugs

\section{Background}

Lymphatic filariasis (LF) is a Neglected Tropical Disease (NTD), caused by parasitic worms and transmitted to humans by mosquitoes. The parasitic filarial nematodes:

\footnotetext{
${ }^{*}$ Correspondence: bamidele992@gmail.com

${ }^{2}$ Department of Zoology (Parasitology Unit), University of Lagos, Akoka, Lagos State, Nigeria

Full list of author information is available at the end of the article
}

Wuchereria bancrofti, Brugia timori and Brugia malayi are the causative agents of these disease (WHO, 2018). Mosquitoes which belong to the genera, Culex, Anopheles, Aedes and Mansonia are vectors implicated in the transmission of these diseases; however, Anopheles and Culex are the primary vectors in Africa (WHO, 2017a, 2017b). LF is a disease that impairs the lymphatic system, resulting in abnormal enlargements of parts of the body: 
lymphodema and hydrocele, causing severe pain, adverse disability and social stigma (WHO, 2019).

Approximately 1.34 billion people in 81 countries are at risk of LF infection, with 120 million people infected. More than 40 million of these are left disfigured and incapacitated by the disease (Okorie et al., 2015; WHO, 2018). A third of the estimated infected people reside in India, Papua New Guinea, South Asia, the Americas the Pacific islands and another third in Africa (Okonofua et al., 2014). The disease is present in about 39 African countries (Iboh et al., 2012). Nigeria is regarded as the third most endemic country in the world, behind Indonesia and India, and bears the highest burden of the disease in Africa (Dogara et al., 2014). Nigeria is estimated to have 114 million of its population at risk of the disease $(\mathrm{FMoH}$, 2015). About $22 \%$ of Nigerians are infected, and 128 million people require preventive chemotherapy (Ojurongbe et al., 2010; Eneanya et al., 2018). LF is present in all 6 geopolitical zones of the country and endemic in 574 Local Government Areas (LGAs), out of which 124 LGAs have been mapped for Mass Drug Administration (Eneanya et al., 2018; Okorie et al., 2015).

In the year 2000, the World Health Organization (WHO) launched the Global Program to Eliminate Lymphatic Filariasis (GPELF). The aim was to eliminate LF by the year 2020 by interrupting transmission, reducing morbidity and preventing disability. In the 1980s, prior to the use of the combination of anthelminthic drugs, LF diagnosis mainly relied on microscopic identification of microfilaria in blood specimens. Treatment was by the administration of DEC for between 12 and 14 days. This treatment was focused on the infected individual (WHO, 2019). Treatment was monotherapy; infection was not cured completely but was able to decrease microfilaria levels remarkably (Ramzy et al., 2019; WHO, 2018). As diagnosis advanced and more complex tools were developed, ivermectin (IVM), albendazole (ALB) and diethylcarbamazine (DEC) were identified as LFactive drugs. These three drugs are therefore currently available for LF treatment: DEC, ALB and IVM (Gypapong et al., 2018). A combination of any two of these drugs has been found to be more efficacious in microfilaria clearance than when they are administered as monotherapy. The effectiveness of these three-drug combinations opened up the possibility of treating the entire population at risk since the absence of $\mathrm{mf}$ in the blood is essential to achieve LF elimination (WHO, 2017a, 2017b). ALB in combination with IVM or DEC was the main drugs available for the large-scale control of LF. However, a combination of all three drugs-ivermectin + diethylcarbamazine + albendazole (IDA)was recently approved for use in settings where LF is not co-endemic with onchocerciasis or loiasis. The Nigerian Lymphatic Filariasis Elimination Programme (NLFEP) of the Federal Ministry of Health (FMoH) began mapping operations in 2003, and they classified Nigeria as endemic based on the report of their survey. The NLFEP, in collaboration with the Carter Centre, had aimed to eliminate the disease in Nigeria by the year, 2015, but so far this has not yet been achieved (Okorie et al., 2015). However, the FMoH now aims to eliminate the disease, by $2030(\mathrm{FMoH}, 2015)$. In Ogun State, LF is endemic in 14 out of the 20 LGAs (Okorie et al., 2015). In order to meet the elimination target of LF, the NLFEP conducted Epidemiological mapping, in 15 LGAs in 2003 and 5 LGAs in 2011, recording a prevalence of $1-4 \%$ in 2003 and $4-10 \%$ in 2011. Results obtained were used to determine the IUs in the LGAs for MDA (Okorie et al., 2015). Control of the disease involves interruption of transmission which is possible through MDA of a single dose of ALB plus either IVM or DEC once yearly for 4-6 years (Okorie et al., 2015, WHO, 2019). A programme area or IU or multiple IUs are considered eligible for Transition Assessment Survey (TAS) which precedes end of MDA, if such IUs have had multiple rounds of MDA. TAS is considered when all of the following criteria are met if at least five rounds of MDA have been implemented, coverage exceeds $65 \%$ of the total population in the IU for each of the five rounds of MDA, and the prevalence of infection in sentinel and spot-check sites is below $1 \%$, assessing microfilaremia. Often times to determine suitability of eligible areas for TAS, a simple, automated algorithm that takes into account a number of variables including population size, scholarity rates, vector species, and others is mounted. Once an area passes and qualifies for TAS, it can stop MDA and then commences transition to post-MDA surveillance (Erlanger et al., 2005; Chu et al., 2013; WHO, 2019). Nigeria began MDA in year 2000 in 4 Local Government Areas (LGAs) and spread effort to 195 LGAs in 2012. The challenge associated with the MDA program has been to achieve and maintain high treatment coverage (Ojurongbe et al., 2010; WHO, 2017a, 2017b). Annual MDA carried out must show adequate levels of coverage, which is estimated to be at least $65 \%$ of the total population in endemic areas. This should ultimately make elimination possible; however, if large proportion of the population is not included or refuses to participate in MDA, a potential parasite reservoir is left untreated, thus allowing the maintenance of transmission (Okorie et al., 2015). People who are systematically noncompliant with MDA threaten the success of the program, especially in areas with high infectivity rate. In most rural areas undergoing ecological 
transformations, particularly as a result of dam construction and irrigation schemes, new breeding sites suitable for the proliferation of the mosquito vector are created. As a result of this, the transmission of LF in such areas is expected to increase (Dogara et al., 2014). Between year 2000 and 2012, MDA was administered to 19,915,586 million people in Nigeria (Iboh et al., 2012; Okorie et al., 2015). One of the greatest challenges confronting the NLFEP is the lack of information on the prevalence of the disease in the country (Iboh et al., 2012). Although a number of studies have been carried out in different parts of the country, most areas of the country have not yet received attention and there is need to aggregate already collated data (Iboh et al., 2012; WHO, 2017a, 2017b).

Despite the ongoing National Elimination Programme, there is still minimal information on the distribution and intensity of LF infection in the country, especially in rural communities, where the disease is deemed endemic (Iboh et al., 2012). This study was conducted to provide a baseline data on the prevalence of LF in Imobi, in Ijebu East LGA, of Ogun State, so as to aid the ongoing national elimination programme, as well as to assess the Knowledge, Attitude and Practice, of people infected with this disease, in the study area.

\section{Methods}

\section{Study area and population}

\section{Description of study}

The study was conducted in a Local Government Health Center in Fetedo, Imobi, Ijebu East Local Government Area of Ogun State, South Western Nigeria. Ogun State shares its eastern border with Ondo State and is bordered by Oyo state in the North and Lagos in the South as well as the Atlantic Ocean. The state falls within the tropical rain forest and wooded Savanna in the Northwest. Ijebu East is a Local Government Area in Ogun State, comprising of several towns. Imobi is one of such towns; its geographical coordinates are latitude $6^{\circ} 36^{\prime} 0^{\prime \prime}$ North and longitude $4^{\circ} 10^{\prime} 0^{\prime \prime}$ East, with an elevation of $48 \mathrm{~m}$ above sea level. The study population consisted of residents of Fotedo Imobi, Ebute Imobi, Terelu, Tioluwo, Denurin, Iba, Okigbode, Itanpampa, Okemakun and Fowoseje all in Imobi, Ijebu East Local Government Area of Ogun State. These residents lack municipal infrastructure, such as tarred roads and drainage systems in their communities, and most of the houses are made of mud and surrounded by vegetation. The people are predominantly Yoruba tribe with farming and fishing as their major occupation, especially Ebute Imobi, that have fishing, as mainstream of the rural economy. They are major producers of cassava which they process into garri, a local staple food.

\section{Study design \\ Population sample}

Population size was determined using Cochrans Formula, at $21 \%$ prevalence, from previous research study (Okonofua et al., 2014; Tekalign, 2018). Systematic random sampling and cluster survey were used to gather the participants at a central point, a Health Center. Advocacy was also carried out, to educate the people on the disease and intimate them about the research study. With the assistance of the health workers, community heads, ward heads and CDA heads, the purpose of research was explained to participants. Informed consent form was given and received from voluntary participants before commencement of the research study. With the assistance of health workers, consenting participants were gathered at a central point: the Fotedo Imobi Health Centre for sample collection and administration of questionnaires. A total of 246 consenting participants responded for the study comprising 79 males and 167 females.

\section{Ethical approval and consent}

Prior to the commencement of the study, ethical approval was given from the LGA Secretariat: IFLG. 45/137.

\section{Parasitological examination}

All was done using WHO operational manual (WHO, 2000). A syringe and needle was used to collect $2 \mathrm{ml}$ of venous blood from the consenting individuals by the health workers, within the period of 10 p.m. and 2 a.m. A tourniquet was tied on the arm of each individual, to ease the flow of blood, and the area was thoroughly swabbed with a cotton wool soaked in ethanol. The $2 \mathrm{ml}$ of blood was then collected and put in a well-labelled EDTA bottle. This was taken to Nigerian Institute of Medical Research (NIMR) Yaba, Lagos, for diagnosis.

\section{Microscopy}

A heparinized capillary tube was used to take $60 \mu \mathrm{L}$ of blood from each consenting participant. This was used to prepare 3 horizontal smears of thick blood film on labelled sterilized glass slides. The blood on the slide was allowed to air dry. The dried slides were deheamoglobinized using distilled water for $3 \mathrm{~s}$ and allowed to air dry. The sample slide was fixed, using ethanol for $30 \mathrm{~s}$. The slides were then stained with $3 \%$ solution of Giemsa stain for $45 \mathrm{~min}$. Microfilaria of Wuchereria bancrofti were identified based on sheathed nuclear, caudal nuclei and bent tail (WHO, 1997a, b; Cheesbrough, 2005). The stained slides were observed using an Olympus CS 21 microscope under $\times 100$ objective lens. Positive slides 
containing microfilariae were confirmed by a trained staff at NIMR, Yaba, Lagos, Nigeria.

\section{Questionnaire administration}

A semi-structured questionnaire was administered, to each participant, prior to the commencement of the tests, conducted at the Local Government Health Center. The first part sought the socio-demographic information of respondents, while the second part aimed to assess respondent's knowledge on the cause, mode of transmission, prevention and treatment of lymphatic filariasis as well as their attitude and practices which may predispose them to the disease.

\section{Statistical analysis}

The data obtained were analysed using Excel 2016 and IBM Statistical Package for the Social Sciences (SPSS) statistics processor, version 23 . The unilabiate data generated were analysed using simple frequencies and percentages, while Chi-squared test and Analysis of Variance (ANOVA) were used for the analysis of multivariate data at a significance level of (0.05). The Micro-Filarial Density (MFD) was calculated as: average number of microfilariae in positive slides per $\mathrm{ml}$ of blood (presuming $60 \mu \mathrm{l}$ per slide $=$ Total number of microfilariae in positive slides $/$ (Total number of positive slide) $\times 16.7$ (WHO, 2017a, 2017b).

\section{Results}

\section{Socio-demographic characteristics}

A total of 246 respondents were sampled, which comprised of 79 (32.1\%) males and 167 (67.9\%) females. Among them, 218 (88.6\%) were married while 28 (11.4\%) were single. The respondents were within the ages of $<18>40$. Majority of the respondents were farmers 148 (60.2\%), followed by traders and artisans (Table 5). Majority of the respondents had only secondary school education 93 (37.8\%) followed by primary 68 (27.6\%) and respondents without formal education (Tables 2,4 ).

Respondents involved in the research study were from ten communities. Fowoseje 64 (26.0\%) were more involving followed by respondents from Tioluwo 48 (19.5\%) and

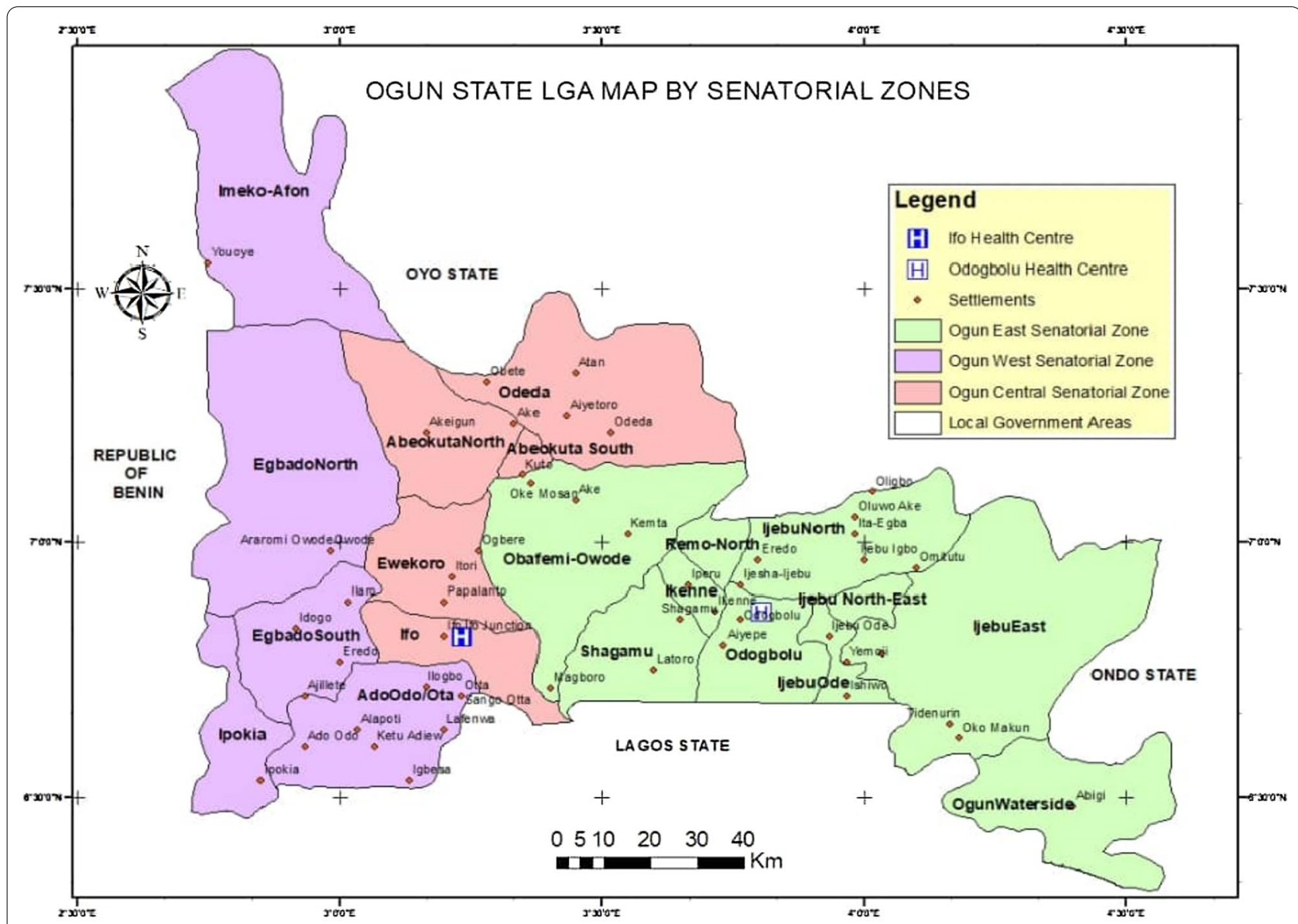

Fig. 1 Map of Ogun State showing the three Local Government Areas Housing the three markets (Ogun State biz, 2020). 
Denurin 46 (18.7\%), while Okemakun 2(0.8\%) and Okigbode were the less involving (Fig. 1). The period of stay of respondents in imobi was highest among those who had lived there for a period, above 10 years 187 (76\%). This showed that most of the respondents have been living there for more than 10 years (Table 4).

Among the 246 voluntary participants that presented themselves for the study, overall prevalence of infection was $50(20.3 \%)$ (Table 1), out of which males 17 (21.5\%) had a higher prevalence of infection than females 33 $(18.8 \%)$, though there was no statistical significance $(p>0.05)$ (Table 2).

The results obtained with respect to age groups revealed that people less than 18 years had the highest prevalence of infection $4(28.6 \%)$ in children while in adults, the stratified age of $18-40$ years 26 (27.4), more than other age group and the difference was statistically significant $(p<0.05)$. This stratified age group is majorly the age distribution of the working class of the population. Single individuals 9 (32.1\%) were also more infected, but there was no significant difference $(p>0.05)$ (Table 2).

In the study area, Okemakun $1(50.0 \%)$ and Okigbode $1(50.0 \%)$ were found to have the highest prevalence of infection. These were followed by Itapanpa $4(36.43 \%)$, then Terelu 4 (36.43\%) and then Terelu 7 (28.0\%) followed then by Tioluwo 6 (20.8) and then Fowoseje 13 (20.3) with the largest population and then Fetedo Imobi 6 (18.8) followed again by Denurin $6(13.0)$ while the least was recorded in Ebute Imobi 1 (9.1\%), but no significance difference was observed between infection and community area or location $(p>0.05)$ (Table 3$)$.

\section{Prevalence of lymphatic filariasis in Imobi, ljebu East Local} Government Area, in relation to occupation

Students 6 (33.3\%) and farmers $35(23.6 \%)$ recorded a higher prevalence, than other occupational groups. Then, the retired 1 (20.0\%) and the artisan $3(15.0)$ and yet still the civil servant 1 (12.5\%), the trader 4 (9.0) and lastly the unemployed recorded low prevalence. There is significant difference between occupation and infection $(p<0.05)$ (Table 4).

Participants that had lived in their respective communities for less than a year had the highest prevalence, 3

Table 1 Prevalence of lymphatic filariasis in Imobi, ljebu East Local Government Area

\begin{tabular}{llll}
\hline Result & $\begin{array}{l}\text { Infectivity } \\
\text { Status }\end{array}$ & Frequency & Percent (\%) \\
\hline Microscopy & Positive & 50 & 20.3 \\
Negative & 196 & 79.7 & \\
Total & 246 & 100.0 & \\
\hline
\end{tabular}

Table 2 Prevalence of lymphatic filariasis in Imobi, ljebu East Local Government Area in relation to age group, sex and marital status

\begin{tabular}{llll}
\hline Variable & \multicolumn{2}{l}{ Microscopy result } & $\boldsymbol{p}$ value \\
\cline { 2 - 3 } & Positive (\%) & Negative (\%) & $\mathbf{0 . 0 5}$ \\
\hline Age group & & & \\
$<18$ & $4(28.6)$ & $11(71.4)$ & \\
$18-40$ & $26(27.4)$ & $69(72.6)$ & 0.043 \\
$>40$ & $20(14.6)$ & $117(85.4)$ & \\
Sex & & & 0.749 \\
Male & $17(21.5)$ & $62(78.5)$ & 0.749 \\
Female & $33(19.8)$ & $134(80.2)$ & \\
Marital status & & & 0.099 \\
Single & $9(32.1)$ & $19(67.9)$ & \\
Married & $41(18.8)$ & $177(81.2)$ & \\
Total & $50(20.3)$ & $196(79.7)$ & \\
\hline
\end{tabular}

(42.9\%). Statistical significance was observed. This has a great implication because less than 1 year in not enough to express infectivity. This observation could implicate that the disease could be imported into the communities (Table 4). There was a significant relationship between lymphatic filariasis and period of stay in the community (Table 5).

A microfilaria density of $25.7 \mathrm{mf} / \mathrm{ml}$ was found in the 50 positive individuals sampled; no significant relationship $(p>0.05)$ was observed between the microfilarial density in males $(24.6 \mathrm{mf} / \mathrm{ml})$ and females $(26.3 \mathrm{mf} / \mathrm{ml})$. The highest microfilarial density $(29 \mathrm{mf} / \mathrm{ml})$ was found in people between the age of 18 and 40 , but there was no statistical significance $(p>0.05)$ (Table 5$)$.

Table 3 Prevalence of lymphatic filariasis in Imobi, ljebu East Local Government Area, in relation to community

\begin{tabular}{lcccc}
\hline Community & \multicolumn{2}{l}{ Microscopy result } & No examined & $\begin{array}{l}\boldsymbol{p} \text { value } \\
\mathbf{0 . 0 5}\end{array}$ \\
\cline { 2 - 3 } & Positive (\%) & Negative (\%) & & \\
\hline Fotedo Imobi & $6(18.8)$ & $26(81.2)$ & 32 & \\
Fowoseje & $13(20.3)$ & $51(79.7)$ & 64 & \\
Itanpampa & $4(36.4)$ & $7(63.6)$ & 11 & \\
Iba & $1(20.0)$ & $4(80.0)$ & 5 & \\
Terelu & $7(28.0)$ & $18(72.0)$ & 25 & \\
Ebute Imobi & $1(9.1)$ & $10(90.9)$ & 11 & \\
Tioluwo & $10(20.8)$ & $38(79.2)$ & 48 & \\
Okemakun & $1(50.0)$ & $1(50.0)$ & 2 & \\
Okigbode & $1(50.0)$ & $1(50.0)$ & 2 & \\
Denurin & $6(13.0)$ & $40(87.0)$ & 46 & \\
Total & $50(20.3)$ & $196(79.7)$ & 246 & \\
\hline
\end{tabular}


Table 4 Prevalence of lymphatic filariasis in relation to occupation, residency, name and causes in Imobi, ljebu East Local Government Area

\begin{tabular}{llll}
\hline Occupation & \multicolumn{2}{l}{ Microscopy result } & \multirow{2}{p}{ value } \\
\cline { 2 - 3 } & Positive (\%) & Negative (\%) & \\
\hline Student & $6(33.3)$ & $12(66.7)$ & \\
Trader & $4(9.0)$ & $40(91.0)$ & \\
Farmer & $35(23.6)$ & $113(76.4)$ & \\
Artisan & $3(15.0)$ & $17(85.0)$ & \\
Civil servant & $1(12.5)$ & $7(87.5)$ & \\
Unemployed & $0(0.0)$ & $3(100.0)$ & \\
Retired & $1(20.0)$ & $4(80)$ & \\
Educational status & & & \\
Primary & 68 & 27.6 & \\
Secondary & 93 & 37.8 & \\
Tertiary & 4 & 1.6 & \\
No formal education & 59 & 24.0 & \\
No response & 22 & 8.9 & 0.490 \\
History of residence & & & \\
$<1$ year & 3 & 42.9 & \\
1-6 years & 6 & 18.2 & \\
$>$ 10 years & 34 & & \\
\hline
\end{tabular}

Respondents' knowledge of the cause of lymphatic

\section{filariasis in the study area}

Majority of the respondents didn't know the English name of the disease 180 (73.2\%) (Table 6). However they seem to be familiar with the disease as they had local names for it, Ipa 62 (25.2\%) and Aran okunrin 4(1.6\%). Most of the respondents 239 (97.2\%) do not know cause of disease. Very few persons reported that the disease was caused by worms 1 (0.4\%), mosquito $3(1.2 \%)$, Stress $2(0.8 \%)$ and poor hygiene $1(0.4 \%)$ (Table 6$)$.

\section{Respondents' knowledge on mode of transmission of LF in the study area}

Most of the respondents 238 (96.7\%) were ignorant of the mode of transmission of the disease. About 123 (50.0\%) opined that the disease was not transmitted by mosquitoes. Only $7(28 \%)$ people were certain of the mode of transmission. There was no response from 122 (49.6\%) about whether the disease is transmissible from one person to the other while $98(39.8 \%)$ responded in the negative. However, 26 (10.6\%) people believed the disease could be transmitted from person to person and $1(0.4 \%)$ said through poor hygiene (Table 6).
Table 5 Microfilaria intensity of participants in Imobi, ljebu East Local Government Area

\begin{tabular}{lclll}
\hline Variable & No examined & $\begin{array}{l}\text { No positive } \\
\text { (\%) }\end{array}$ & $\begin{array}{l}\text { Microfilarial } \\
\text { density }(\mathbf{m f} / \\
\text { ml) }\end{array}$ & P value \\
\hline Age group & & & & \\
$<18$ & 14 & $4(28.6)$ & 20.9 & \\
$18-40$ & 95 & $26(27.4)$ & 29 & \\
$>40$ & 137 & $20(14.6)$ & 22.5 & \\
Total & 246 & $50(20.3)$ & 25.7 & 0.321 \\
Sex & & & & \\
Male & 79 & $17(21.5)$ & 24.6 & \\
Female & 167 & $33(19.8)$ & 26.3 & 0.709 \\
Mean/aver- & 246 & $50(20.3)$ & 25.7 & \\
$\quad$ age & & & & \\
\hline
\end{tabular}

Table 6 Respondents' knowledge on transmission of LF

\begin{tabular}{|c|c|c|c|}
\hline Variable & Frequency & Percentage (\%) & $P$ value \\
\hline \multicolumn{4}{|c|}{ Local name for elephantiasis } \\
\hline Ipa & 62 & 25.2 & \\
\hline Aran okunrin & 4 & 1.6 & \\
\hline Don't know & 180 & 25.5 & 0.000 \\
\hline \multicolumn{4}{|c|}{ Cause of disease } \\
\hline Worm & 1 & 0.4 & \\
\hline Mosquito & 3 & 1.2 & \\
\hline Stress & 2 & 0.8 & \\
\hline Poor hygiene & 1 & 0.4 & \\
\hline Don't know & & 97.2 & 0.001 \\
\hline \multicolumn{4}{|c|}{ Can mosquitoes transmit the disease } \\
\hline Yes & 31 & 12.6 & \\
\hline No & 123 & 50.0 & \\
\hline No response & 92 & 37.4 & 0.045 \\
\hline \multicolumn{4}{|c|}{ Mode of transmission } \\
\hline Mosquitoes & 7 & 2.8 & \\
\hline Poor hygiene & 1 & 0.4 & \\
\hline Don't know & 238 & 96.7 & 0.045 \\
\hline \multicolumn{4}{|c|}{ Can the disease be transmitted from person to person } \\
\hline Yes & 26 & 10.6 & \\
\hline No & 98 & 39.8 & \\
\hline No response & 122 & 49.6 & 0.045 \\
\hline Total & 246 & 100.0 & \\
\hline
\end{tabular}

\section{Respondents' knowledge on prevention and treatment} of lymphatic filariasis

A greater proportion of the respondents did not believe that the disease can be prevented 87 (82.1\%). However, some of them believed it can be transmitted through the following measures, medicine 2 (1.9\%), hygiene 1 $(0.9 \%)$, self-care $1(0.9 \%)$, operation/surgery 1 (0.9\%) 
Table 7 Respondents' knowledge on prevention and treatment of lymphatic filariasis

\begin{tabular}{|c|c|c|c|}
\hline Variable & Frequency & Percentage (\%) & $\begin{array}{l}P \text { value } \\
0.05\end{array}$ \\
\hline \multicolumn{4}{|c|}{ Can mosquitoes transmit the disease } \\
\hline Yes & 106 & 43.1 & \\
\hline No & 42 & 17.1 & \\
\hline No response & 98 & 39.8 & \\
\hline \multicolumn{4}{|l|}{ Preventive measures } \\
\hline Use of bednets & 12 & 11.3 & 0.0467 \\
\hline Medicine & 2 & 1.9 & \\
\hline Hygiene & 1 & 0.9 & \\
\hline Self-care & 1 & 0.9 & \\
\hline Operation/surgery & 1 & 0.9 & \\
\hline Hospital visits & 2 & 1.9 & \\
\hline Don't know & 87 & 82.1 & \\
\hline \multicolumn{4}{|l|}{ Use of LLIN } \\
\hline Yes & 213 & 86.6 & 0.0467 \\
\hline No & 33 & 13.4 & \\
\hline \multicolumn{4}{|l|}{ Can the disease be treated } \\
\hline Yes & 90 & 36.6 & \\
\hline No & 51 & 20.7 & \\
\hline No answer & 105 & 42.7 & \\
\hline Drugs & 9 & 10.0 & \\
\hline Don't know & 64 & 72.1 & \\
\hline \multicolumn{4}{|c|}{ Heard of albendazole, ivermectin and DEC } \\
\hline Yes & 13 & 5.6 & \\
\hline No & 233 & 94.7 & 0.035 \\
\hline \multicolumn{4}{|c|}{ Taken any of the above medicine } \\
\hline Yes & 10 & 5.6 & \\
\hline No & 236 & 95.9 & \\
\hline \multicolumn{4}{|c|}{ Prevalence of LF in relation to use of anti-filarial drug } \\
\hline Albendazole only & 1 & & \\
\hline Albendazole and ivermectin & 0.0 & & \\
\hline
\end{tabular}

and hospital visits 2 (1.9\%). Most of the respondents 90 (36.6\%) believed that the disease was treatable, 17 (18.9\%) said through hospital visits and $9(10.0 \%)$ through the use of drugs (Table 7). The respondents 213 (86.6\%) made use of LLIN while $12(11.3 \%)$ believed that the disease could be prevented by the use of bed nets. Both parameters were significantly related to infection at $p<0.05$ (Table 7).

Most of the respondents 233 (94.7\%) had not heard of any of the anti-filarial drugs or had 236 (95.9\%) taken them. However, 13 (5.3\%) people had heard of either albendazole or ivermectin, and diethylcarbamazine $10(4.1 \%)$ of them had been treated with them, out of which $2(20 \%)$ has been treated with only albendazole and $8(80 \%)$ with albendazole and ivermectine as multiple drug therapy (Table 7 ).
Prevalence was also found to be significantly lower in people that had received treatment with albendazole and ivermectin $0(0.0 \%)$ than in people treated with albendazole alone 1 (50.0\%) (Table 7).

Use of anti-filarial drug in relation to community participation Out of the 10 communities in Imobi, Ijebu North East Local government Area of Ogun State, sampled, five, Fawoseje, Itanpanpan, Okigbode and Denurin, had $0(0.0 \%)$ participation for anti-filarial drugs. The other five that have participated, Fetedo, Imobi 5 (15.6\%), Ebute 2 (18.2\%), Toluwo 2 (4.2\%), Okemekun 1 (50.0\%) and Iba 1 (20.0\%), had participation threshold requirement of less than $80 \%$ by WHO standard (Fig. 2).

At least one person had received treatment with antifilarial drugs from five out of the ten communities that were sampled in the study, implying that MDA might have begun in Imobi, but efforts need to be intensified (Fig. 3).

\section{Discussion}

This research work has been able to provide a baseline data for LF in Imobi in Ijebu East local Government of Ogun State to reposition elimination strategy. The microfilaria type is noteworthy Wuchereria bancrofti, as has been reported in previous research studies in the State (Eneanya et al., 2018; Okonofua et al., 2014; Okorie et al., 2015).

The suitability of environmental factors and certain human activities has been attributed to sustainable factors of vectors of LF (Okonofua et al., 2014). Imobi because of their major occupation of farming is predisposed to all these enhancing factors to LF, and for elimination to be considered viable, there is need to consider these prevailing factors.

An overall prevalence of $20.3 \%$ was recorded this study, which is lower than the $27.0 \%$ prevalence reported by Adekunle et al. (2016) but higher than the prevalence of $4.0 \%$ and $2.4 \%$ reported previously in Ado-Odo/ Ota LGA and in Abeokuta South LGA, Ogun State, respectively (Okorie et al., 2015). It is also higher than the prevalence of $17.0 \%$ reported in Sowo village, in Obafemi Owode, Ogun State (Ojurongbe et al., 2010). Many factors could be attributed to this. These could be because of the Knowledge, Attitudes and Practices of participants to LF. Others could be that there are no previous data to compare with, while still others are that Imobi is a town of many rivers and these rivers are used for the major occupation of people in the study area which is farming; these equally serve as breeding sites for vectors of parasite. Previous studies have reported such observation was most rural areas undergoing ecological transformations; particularly as a result of dam construction and irrigation schemes, they have become breeding sites for vectors 


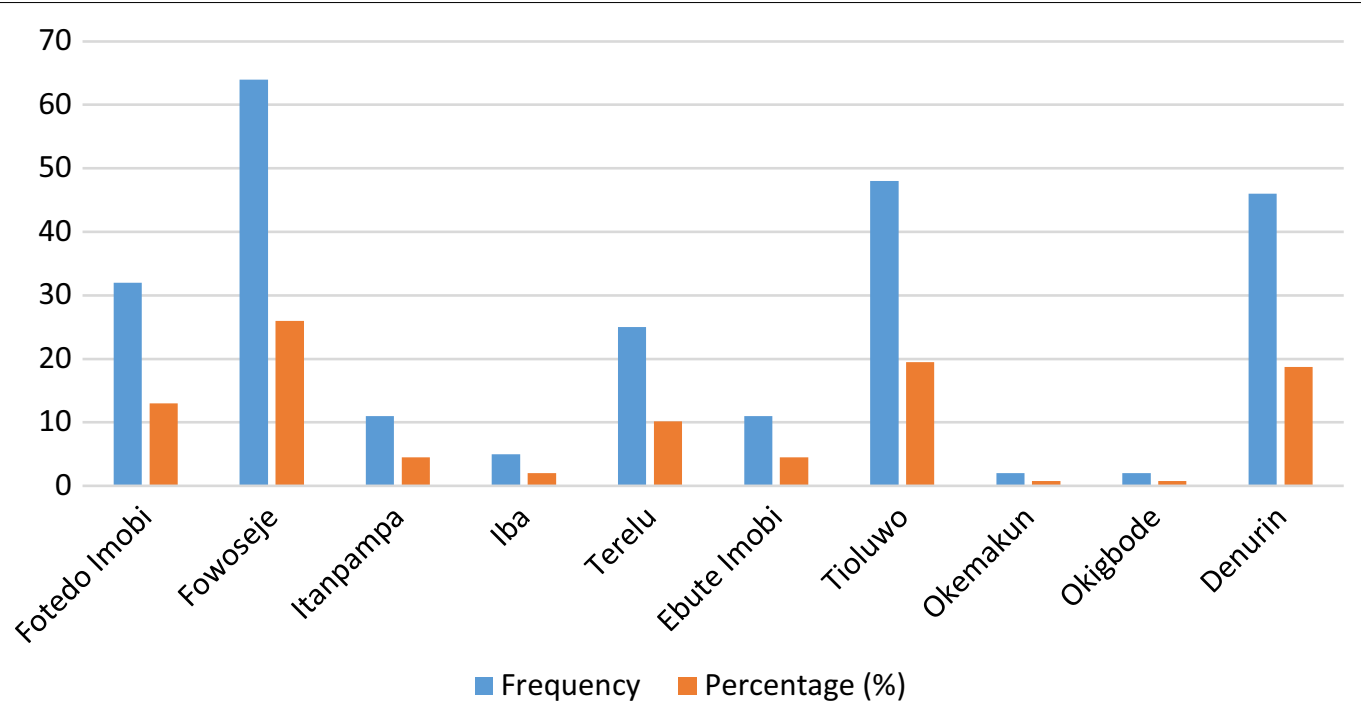

Fig. 2 Number of communities sampled in the study area

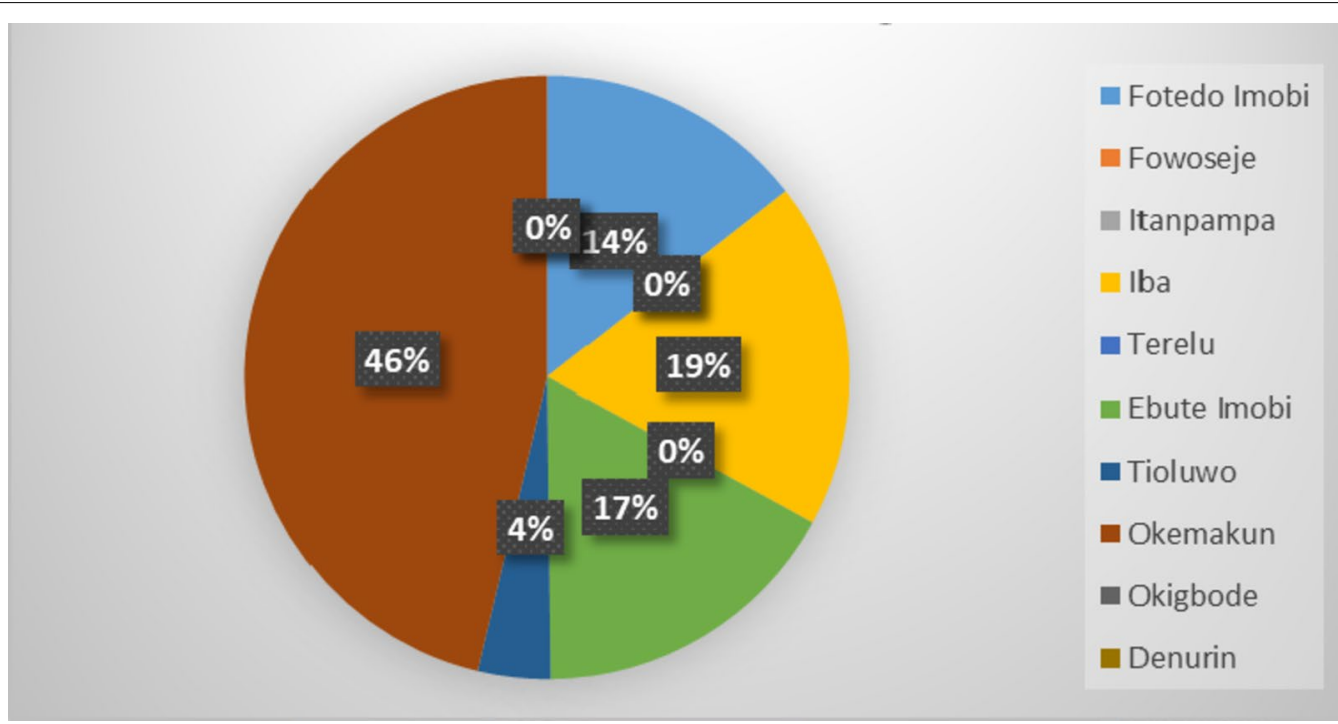

Fig. 3 Use of anti-filarial drug in relation to community participation

of LF (Erlanger et al., 2005; infectionlandscape, 2020). Transmission of LF in Imobi could also be linked to the fact that the study area consists of rural communities that have their houses, surrounded by vegetation and stagnant waters with no clear demarcation between houses; hence, there is ease of transmission, of LF. Previous reports have indicated such occurrences (Amaechi, 2014; Ramzy et al., 2019; WHO, 2017a, 2017b).

Infection was higher in males $(21.5 \%)$ than in females (19.8\%), though there was no statistical significance. A similar finding was also reported by Dogara et al. (2012) in Kano State, Nigeria. Adekunle et al. (2016) observed a similar result with $(27.0 \%)$ of males and $(26.0 \%)$ of females. Occupational, behavioural, immunological and hormonal factors could be attributed, as possible predisposing factors. However, in this research study males and females could be assumed to have an equal chance of exposure to vectors as there was no statistical difference.

Also with respect to age, prevalence was significantly higher in younger age groups $(28.6 \%)$ than in older age groups (14.6\%). However, among adult population, prevalence of infection is highest within the stratified ages 
(18-40 years) which is the peak of the working population. This aligned with previous reported literature on LF (Amaechi, 2014; Ojurongbe et al., 2010; Okorie et al., 2015). However, one common trend observed in the above studies is that infection rate is higher in productive ages, so exposure to infection may occur during the course of daily activities and work.

In the research study, it was also observed that the farmers and the students were mostly infested and this also was significant to rate of infection. The farmers must have been infected through irrigational farming, so also is the students who were helping their parents. This was also in line with previous research findings, conducted in Malaysia (Al-Abd et al., 2014).

Another striking observation made in this research study was that participants that had lived in their respective communities for less than a year had the highest prevalence. This result also was statistical significance to rate of infection. LF has a period of infestation which is higher than 1 year (Gypapong et al., 2018). For those in the community, for less than 1 year to be infected, it could have only been made possible, if diseases are imported into the communities. Ogun State as a gate way state allows influx of people from neighbouring countries, and the possibility of these immigrants coming in without proper screening for LF may have been major contributing factor to controlling infection.

The total microfilarial density $(25.7 \mathrm{mf} / \mathrm{ml})$ observed in this study is higher than those observed by Okorie et al. (2015) in Abeokuta South $(23.9 \mathrm{mf} / \mathrm{ml})$ but lower than the microfilarial density of $30.6 \mathrm{mf} / \mathrm{ml}$ in Ado-Odo Ota (Okonofua et al., 2014). Microfilarial density and microfilarial prevalence have been recommended as the best indicators for the epidemiology, management and control of lymphatic filariasis (Okonofua et al., 2014; Okorie et al., 2015).

People that made use of LLIN registered lower prevalence. This was significantly related to rate of infection at $p<0.05$. Use of LLIN has been shown to shorten the life span of vectors thereby interrupting transmission. However, reduced filarial density in vectors is the primary index for measuring the efficiency of LLINs in LF prevention (Odermatt et al., 2008; Ashton et al., 2011).

The study participants have benefitted from the ongoing MDA by National control programmes with albendazole and ivermectin $(\mathrm{FMoH}, 2015)$. This is obvious from the response of some of the participants in the study area. Although very few, some of the participants indicated having taken both the monotherapy of albendazole only and the multiple drug therapy of albendazole with ivermectin which is the drug administered for MDA, in Ogun State which is co-endemic with onchocerciasis (Ojurongbe et al, 2010; Subramanian, 2004). It was also observed that the population coverage was below $65 \%$, of the total population in the IU, for each of the five rounds of MDA. The prevalence of infection in the study area was also above $1 \%$ assessing microfilaremia with microscopy. This is above WHO's threshold level for stopping MDA (WHO, 2018).

The participants in the study area that engaged in MDA was majorly monotherapy and it prevalence of infection was still observed. And it has been observed from previous literature that infection was not cured completely through monotherapy but was only able to decrease microfilaria levels remarkably (Ramzy et al., 2019; WHO, 2019). Also those that engaged in multiple drug regimens did not participate in the 5-6 years rounds of MDA. Previous literature has reported that, for the effectiveness of these three-drug combination therapy, participation in MDA should be done annually for 5 years, for the absence of $\mathrm{mf}$ in the blood to be achieved. This is essential to achieve LF elimination (Ramzy et al., 2019; WHO, 2017a, 2017b). No microfilariae was found in individuals that had received a combination of ivermectin and albendazole, while one person out of the two people that had received albendazole alone was still positive for LF. A study conducted by (Dembele et al., 2010; WHO, 2020) indicated that an increased frequency and higher dose of a combination of ivermectin and albendazole amplified the chances of microfilariae suppression. It has been reported by Marcfarlane et al. (2019) that the use of albendazole alone makes little or no difference in clearing microfilaria or adult worms even after 12 months posttreatment. At least one person had received treatment with anti-filarial drugs from five out of the ten communities that were sampled in the study, implying that MDA might have begun in Imobi, but efforts need to be intensified. Nevertheless, the period between treatment and the time of the study was not taken into consideration during this research.

The results from the Knowledge, Attitude and Practices (KAP) studies show that majority of the residents of Imobi were unaware of the knowledge, causes, transmission pattern, prevention and treatment of LF. This seems to be in line with finding some endemic areas across the country (Dogara et al., 2014; Okorie et al., 2015; Amaechi et al., 2016).

\section{Conclusions}

The results of this study give baseline data for the prevalence of LF in Imobi, Ijebu East LGA of Ogun State. Prevalence of infection was also higher than $1 \%$ the threshold level of stopping MDA and less than expected coverage by WHO operational guidelines. Hence, it is imperative that the ongoing MDA by National Control Programs be continued in the community. There is also 
need to carry out sensitization that will be all encompassing and should be community based and from the grassroots level which involve unit leaders, heads of wards, Community Development Chairman to mention a few for effective mobilization and participation. Given the prevalence of LF in the study area, it is essential for MDA to be carried out, as well as vector control activities in order to reduce the transmission rate and to meet the elimination target that has been set for the disease. Mass awareness campaigns through various media is also very important in making sure people in affected areas take necessary precautions against getting infected and reinfection. The government as well as non-governmental organizations also have a crucial role to play in the area of funding of research and treatment, including the organization of awareness programs on the disease. Also the government should create a screening process, for people coming into the state from outside the state because of the strategic positioning of Ogun State as the Gateway State.

\begin{abstract}
Abbreviations
MDA: Mass Drug Administration; LF: Lymphatic filariasis; GPELF: Programme for elimination of lymphatic filariasis; WHO: World Health Organizations; LGA: Local Government Area; KAP: Knowledge Attitude and Practices; NTDS: Neglected tropical diseases; NLFEP: The Nigerian Lymphatic Filariasis Elimination Programme; DEC: Diethycarbamizine; ALB: Albendazole; TAS: Transition Assessment Survey; NIMR: Nigerian Institute of Medical Research.
\end{abstract}

\section{Acknowledgements}

The authors acknowledged the magnanimity of the Vice Chancellor of Crawford University, lgbesa, for his love and kindness during this research.

\section{Authors' contributions}

$\mathrm{AB}, \mathrm{ET}$, and $\mathrm{AO}$ designed and conceptualized the work, while $\mathrm{OC}$ together with $A B$ and $E T$ went to the field to carry out the research. The manuscript was written by $\mathrm{OC}$ while contributions and corrections were done by all the authors. All authors have approved the manuscript for publication.

\section{Funding}

The authors declare no funding body for the research.

\section{Availability of data and materials}

All data presented are original and are available on request from Department of Zoology, University of Lagos.

\section{Declarations}

\section{Ethics approval and consent to participate}

Prior to the commencement of the study, ethical approval was given from the LGA Secretariat: IFLG. 45/137. Medical director in Ogbere Local government, Primary health care unit in Fetedo. District heads and village heads through assistance of the health workers. Advocacy was done before the commencement of the work, and verbal consent of the participant was obtained and they willingly participated in the research.

\section{Consent for publication}

Not applicable.

\section{Competing interests}

The authors report no competing interest.

\section{Author details}

${ }^{1}$ Department of Biological Sciences, Crawford University, Igbesa, Ogun State, Nigeria. ${ }^{2}$ Department of Zoology (Parasitology Unit), University of Lagos, Akoka, Lagos State, Nigeria.

Received: 11 June 2020 Accepted: 22 September 2021

Published online: 14 October 2021

\section{References}

Adekunle, N. O., Sam-Wobo, S. O., Adeleke, M. A., Ekpo, U. F., Davies, E., Ladokun, A. O., Amaechi, E. C., Ohaeri, C. C., Ukpai, O. M., Nwachukwu, P. C., \& Ukoha, U. K. (2016). Lymphatic filariasis: Knowledge, attitude and practices among inhabitants of an irrigation project community, North Central Nigeria. Asian Pacific Journal of Tropical Disease, 6(9), 709-713.

Al-Abd, N. M., Nor, Z. M., Ahmed, A., Al-Adhroey, A. H., Mansor, M., \& Kassim, M. (2014). Lymphatic filariasis in Peninsular Malaysia: A cross-sectional survey of the knowledge, attitudes, and practices of residents. Parasites \& Vectors, 7,545.

Amaechi, E. C. (2014). Lymphatic filariasis among the Ndoki people of Ukwa East Local Government Area, Abia State, Eastern Nigeria. Nigerian Journal of Parasitology, 35(1), 83-88.

Amaechi, E. C., Ohaeri, C. C., Ukpai, O. M., Nwachukwu, P. C., \& Ukoha, U. K. (2016). Lymphatic filariasis: knowledge, attitude and practices among inhabitants of an irrigation project community, North Central Nigeria. Asian Pacific Journal of Tropical Disease, 6(9), 709-713.

Ashton, R. A., Kyabayinze, D. J., Opio, T., Auma, A., Edwards, T., Matwale, G., Onapa, A., Brooker, S., \& Kolaczinski, J. H. (2011). The impact of mass drug administration and long-lasting insecticidal net distribution on Wuchereria bancrofti infection in humans and mosquitoes: an observational study in northern Uganda. Parasites \& Vectors, 4, 119-134.

Cheesbrough, M. (2005). Medical laboratory manual for tropical countries 1 ELBS/Butterworth.Kent.

Chu, B. K., Deming, M., Biritwum, N. K., Bougma, W. R., Dorkenoo, A. M., et al. (2013). Transmission assessment surveys (TAS) to define endpoints for lymphatic filariasis mass drug administration: A multicenter evaluation. PLoS Neglected Tropical Diseases, 7, 2584.

Dembele, B., Coulibaly, Y. I., Dolo, H., Konate, S., Coulibaly, S. Y., Sanogo, D., Soumaoro, L., Coulibaly, M. E., Doumbia, S. S., Diallo, A. A., Traore, S. F., Keita, A. D., Fay, M. P., Nutman, T. B., \& Klion, A. D. (2010). Use of high-dose, twice-yearly albendazole and ivermectin to suppress Wuchereria bancrofti microfilarial levels. Clinical Infectious Diseases, 51(11), 1229-1235.

Dogara, M. M., Nock, H. I., Agbede, R. I. S., \& Ndams, I. S. (2014). Survey of knowledge, attitudes and perceptions (KAPs) of lymphatic filariasis patients in Kano State, Nigeria. International Research Journal of Public and Environmental Health, 1(10), 207-210.

Dogara, M. M., Nock, H. I., Agbede, R. I. S., Ndams, S. I., \& Joseph, K. K. (2012). Prevalence of lymphatic filariasis in three villages in Kano State, Nigeria. The Internet Journal of Tropical Medicine., 8(1), 12-28.

Eneanya, O. A., Cano, J., Dorigatti, I., Anagbogu, I., Okoronkwo, C., Garske, T., \& Donnelly, C. A. (2018). Environmental suitability for lymphatic filariasis in Nigeria. Parasites \& Vector, 11, 513

Erlanger, T. E., Keiser, J., Caldas De Castro, M., Bos, R., Singer, B. H., \& Tanner, M. (2005). Effect of water resource development and management on lymphatic filariasis, and estimates of populations at risk. American Journal of Tropical Medicine and Hygiene, 73(3), 523-533.

FMoH. (2015). Nigeria master plan for neglected tropical diseases (NTDs) 2015-2020, (Vol. 19), 48.

Gypapong, J. O., Owusu, I. O., da-Costa Vroom, F. B., Mensah, E. O., \& Gyapong, M. (2018). Elimination of lymphatic filariasis: current perspectives on mass drug administration. Research and Reports in Tropical Medicine. 9, 25-33.

Iboh, C. I., Okon, O. E., Opara, K. N., Asor, J. E., \& Etim, S. E. (2012). Lymphatic filariasis among the Yakurr people of cross river state, Nigeria. Parasites \& Vectors, 5(1), 203.

Marcfarlane, C. L., Budhathoki, S. S., Johnson, S., Richardson, M., \& Garner, P. (2019). Albendazole alone or in combination with microfilaricidal drugs for lymphatic filariasis. Cochrane Database Systematic Review, 19(1), 67-79.

Odermatt, R., Leang, B., Bin, T., Bunkea, K., \& Socheat, D. (2008). Prevention of lymphatic filariasis with insecticide-treated bednets in Cambodia. Annals of Tropical Medicine \& Parasitology, 102(2), 135-142. 
Ojurongbe, O., Akinbo, J. A., Ogiogwa, J. A., Bolaji, A. S., \& Adeyeba, O. A. (2010). Lymphatic filariasis in a rural community in Nigeria: A challenge ahead. African Journal of Medicine and Medical Sciences, 39, 179-183.

Okonofua, C., Morenikeji, O., \& Oyetunde, S. (2014). Filariasis and associated morbidities in rural communities of Ogun State, Southwestern Nigeria. Travel Medcine and Infectious Diseases, 12(1), 95-10.

Okorie, P. N., Davies, E., Ogunmola, O. O., Ojurongbe, O., Saka, Y., Okoeguale, B. \& Braide, E. I. (2015). Lymphatic filariasis baseline survey in two sentinel sites of Ogun state, Nigeria. The Pan African Medical Journal, 20, 397.

Ramzy, R. M. R., Kamal, H. A., Hassan, M. A., \& Haggag, A. A. (2019). Elimination of lymphatic filariasis as a public health problem from the Arab Republic of Egypt. Acta Tropica, 199, 1121.

Subramanian, S. (2004). Modelling lymphatic filariasis: Transmission and control. Ipskamp, Enschede, 130pp.

Tekalign. (2018). https://www.statisticshowto.com.

WHO, World Health Organization. (1997a). Elimination of lymphatic filariasis as a public health problem - resolution of the executive board of the WHO. 50th World Health Assembly, May 6 1997, Geneva, 50; 29.

WHO (1997b). Bench aid for the diagnosis of filarial infection, p. 7.

WHO, Department of Communicable Disease Prevention, Control and Eradication. (2000). Preparing and implementing a national plan to eliminate filariasis in countries where onchocerciasis is co-endemic. World Health Organization. Retrieved March 20, 2019, from http://www.who.int/lymph atic_filariasis/resources/who_cds_cpe_cee_2000.16/en/.
WHO. (2017) Republic of the Marshall Islands eliminates lymphatic filariasis as a public health problem. World Health Organization. Retrieved June 3, 2019, from https://www.who.int/westernpacific/news/detail/30-03-2017republic-of-the-marshall-islands-eliminates-lymphatic-filariasis-as-apubl ic-health-problem.

WHO. (2017). Global programme to eliminate lymphatic filariasis. World Health Organization. Retrieved May 29, 2019, from http://www.who.int/lymph aticfilariasis/elimination-programme/en/.

World Health Organization. (2018). Retrieved 19 December, 2019, from http:// www.who.int/lymphatic_filariasis/resources/who_wer9344/en/.

World Health Organization. (2019). Global programme to eliminate lymphatic filariasis: progress report, 2018. Weekly Epidemiological Record, 94(41), 457-472.

World Health Organization. (2020). Regional Office for Africa Expanded Special ProjectforElimination on Neglected Tropical Diseases (ESPEN) Annual Report, 2019 Brazzaville World Health Organization Regional Office for Africa 2020

\section{Publisher's Note}

Springer Nature remains neutral with regard to jurisdictional claims in published maps and institutional affiliations.

\section{Submit your manuscript to a SpringerOpen ${ }^{\circ}$ journal and benefit from:}

- Convenient online submission

- Rigorous peer review

- Open access: articles freely available online

- High visibility within the field

- Retaining the copyright to your article

Submit your next manuscript at $\boldsymbol{\nabla}$ springeropen.com 